\title{
Characterization and Conditioning of SSPX Plasma Facing Surfaces
}

D. Buchenauer, B. E. Mills, R. Wood ${ }^{a}$, S. Woodruffa, D. N. Hill', E. B. Hooper ${ }^{a}$, and D. F.

Cowgill

Sandia National Laboratories, Livermore, CA ${ }^{a}$ Lawrence Livermore National Laboratory, Livermore, CA
The submitted manuscript bas boer. authored by a contractor of the Unitec States Government under contract. Accordingly the United States Gov. ernment retains a non-exclusive. rogalty-free license to publish or re. produce the published form of this contribution, or allow others to do so, for United States Governmont par-

The Sustained Spheromak Physics Experiment (SSPX) will examine the confingomentit properties of spheromak plasmas sustained by DC helicity injection. Understanding the plasma-surface interactions is an important component of the experimental program since the spheromak plasma is in close contact with a stabilizing wall (flux conserver) and is maintained by a high-current discharge in the coaxial injector region. Peak electron temperatures in the range of $400 \mathrm{eV}$ are expected, so the copper plasma facing surfaces in SSPX have been coated with tungsten to minimize sputtering and plasma contamination. Here we report on the characterization and conditioning of these surfaces used for the initial studies of spheromak formation in SSPX.

The high-pressure plasma-sprayed tungsten facing the SSPX plasma was characterized in-situ using beta-backscattering and ex-situ using laboratory measurements on similarly prepared samples. Measurements indicate that water can be desorbed effectively through baking while hydrocarbon / oxide removal using glow discharge and shot conditioning is slow due to the coating's high porosity.

\section{Introduction}

Over the past few years, improvements in performance in many tokamak experiments have resulted from the heightened attention paid to understanding wall conditions. Techniques for wall conditioning have reduced plasma impurity levels and lowered recycling of hydrogenic 
fuels, leading to improved confinement modes such as the super shot and VH-mode. It is to be expected then that similar techniques will be needed to improve the performance of other innovative confinement devices included in the widening scope of the U.S. Fusion Science program. While similarities to the tokamak exist, differences in the edge plasma and magnetic configuration of these experiments and renewed interest in refractory materials (due to codeposition of hydrogen with carbon) present new challenges to optimize plasma-wall interactions in these devices. The present work describes the initial efforts to characterize and condition the plasma facing surfaces in one such device, the Sustained Spheromak Physics Experiment (SSPX) at Lawrence Livermore National Laboratories.

The motivation for SSPX can be found in recent articles ${ }^{1,2,3}$. Initial experiments aimed toward establishing the spheromak magnetic configuration began in April 1999 and were accompanied by significant periods of wall conditioning. During this initial period of operations (through August 1999) and prior to the second period (October 1999), the diagnostic capabilities of the machine were limited and residual gas analysis was used as the primary indication of the effectiveness of wall conditioning. More recent analysis of the plasma impurity levels and plasma density will be reported by Wood ${ }^{4}$.

\section{Experimental setup}

The configuration of SSPX is similar to that of CTX $X^{5}$ and is shown schematically in Figure 1. To form a spheromak plasma, a voltage is applied across the gap between the injector inner (negative) and outer (ground) electrodes as gas $\left(\mathrm{H}_{2}, \mathrm{D}_{2}\right.$, or $\mathrm{He}$ ) in introduced from 4 to 8 highspeed gas valves mounted on the $45^{\circ}$ shelf near the region labeled "Injector Discharge Region. $\mathbf{J}$ $\times \mathbf{B}$ forces push the plasma out of the injector toward the flux conserver where reconnection 


\section{DISCLAIMER}

This report was prepared as an account of work sponsored by an agency of the United States Government. Neither the United States Government nor any agency thereof, nor any of their employees, make any warranty, express or implied, or assumes any legal liability or responsibility for the accuracy, completeness, or usefulness of any information, apparatus, product, or process disclosed, or represents that its use would not infringe privately owned rights. Reference herein to any specific commercial product, process, or service by trade name, trademark, manufacturer, or otherwise does not necessarily constitute or imply its endorsement, recommendation, or favoring by the United States Government or any agency thereof. The views and opinions of authors expressed herein do not necessarily state or reflect those of the United States Government or any agency thereof. 


\section{DISCLAIMER}

Portions of this document may be illegible in electronic image products. Images are produced from the best available original document. 
occurs to form the spheromak. Given the high currents supplied at the injector (up to $450 \mathrm{kA}$ ) and expected in the main plasma (up to 1.2 MA), the solid copper flux conserver has been carefully shaped to minimize dissipation and provide stabilization of global MHD modes. A more detailed description of spheromak formation schemes can be found in the recent book by Bellan ${ }^{6}$.

The plasma facing surfaces in SSPX include regions in the injector and the main spheromak volume. All of these surfaces are made from $1.27 \mathrm{~cm}$ thick copper $(\mathrm{OHFC})$ and protected with a $100 \mu \mathrm{m}$ thick, high-pressure plasma-sprayed (HPPS) tungsten coating. The protection derives from the higher sputtering threshold and melting temperature for tungsten compared to copper. The surface area of this coating exposed to the formation region is comparable to that exposed to the main spheromak plasma (see Table 1).

\begin{tabular}{|c|c|c|c|c|}
\hline & Inner Electrode & Outer Electrode & Flux Conserver \\
\hline Main spheromak plasma & & $0.36 \mathrm{~m}^{2}$ & $0.71 \mathrm{~m}^{2}$ & $4 \mathrm{~m}^{2}$ \\
\hline Plasma formation region: & & & & \\
\hline Upper $\left(\mathrm{d}_{\text {cap }}=10 \mathrm{~cm}\right)$ & & $0.54 \mathrm{~m}^{2}$ & $0.70 \mathrm{~m}^{2}$ & \\
\hline Lower $\left(\mathrm{d}_{\text {qap }}=16 \mathrm{~cm}\right)$ & & $1.1 \mathrm{~m}^{2}$ & $1.6 \mathrm{~m}^{2}$ & \\
\hline
\end{tabular}

Table 1

The HPPS tungsten coating was fabricated at Hayden Corporation (West Springfield, MA) by introducing $44 \mu \mathrm{m}$ grain tungsten powder into an argon plasma torch (in air). While multiple passes of the torch can be used to build up a thick coating ( $\approx 10 \mu \mathrm{m} /$ pass), the resultant porosity is known to be higher than that of low pressure techniques ${ }^{7}$ and oxide formation between the layers can occur. The porosity is beneficial, however, in reducing thermal stresses that result from the thermal expansion mismatch between the tungsten and copper ( $\times 4$ at $293 \mathrm{~K}$ ). Similar coatings were used on the CTX cathode and in HIT. The $100 \mu \mathrm{m}$ thickness was based on the 
thickness-dependent, nitrogen desorption rates for the coating and SSPX vessel pump-out needs. 120

\section{Characterization of HPPS tungsten}

Characterization of the plasma facing surfaces in SSPX has been done by both in-situ methods and laboratory techniques using similarly prepared coatings on $1.27 \mathrm{~cm}$ thick copper. Samples were also examined by thermal desorption spectroscopy for comparison with residual gas analysis during SSPX bake-out. Due to the high porosity of the coating, no solvent cleaning was attempted on the coated components installed in SSPX.

During initial inspection of the HPPS tungsten, variations in texture were observed on the flux conserver, suggesting that there were thickness variations. To determine the uniformity of the coating, $\beta$ back-scattering measurements ${ }^{8}$ were done on all components and calibrated using sample coatings of varying thickness. The hand-held device uses a gas proportional counter to measure the back-scattering of electrons from a Strontium $90 \beta$. source.

Toroidal measurements along the bottom of the flux conserver and at three heights on the inner electrode (Figure 2) indicated that the uniformity of the coating was within the measurement accuracy (approximately 15\%). In addition, spot measurements on all coated components showed that the coating thickness exceeded the $100 \mu \mathrm{m}$ nominal value on all surfaces except on the inner electrode in the "Injector Discharge Region" (25 and $41 \mathrm{~cm}$ from the end of the electrode), where values were about $15 \%$ below nominal. Subsequent measurements made at the end of the initial operations period did not show any erosion of these surfaces; however, the appearance of the inner electrode (used as the cathode) changed from the as-delivered dull gray 
to a shiny appearance. The role of shot conditioning in producing this change will be described below.

Samples of $125 \mu \mathrm{m}$ thick HPPS tungsten were studied using optical microscopy and scanning electron microscopy (SEM) to evaluate the coverage and structure of the coating. The surface topology revealed lamella structures characteristic of plasma-sprayed materials (see Figure 3). The apparent porosity is connected to the surface and results in a larger effective surface area (up to 6 times the planer area using features above $1 \mu \mathrm{m}$ ). Lower porosity regions were also observed that contain larger spherical structures, indicative of inadequate melting of the tungsten powder in the plasma torch. The high porosity and lack of melting in some areas can result in low thermal conductance in the coating and between the coating and copper substrate.

Surface measurements done by Auger Electron Spectroscopy (AES) on an outer layer lamella showed concentrations of oxygen and carbon on the outer surfaces ( $45 \%$ and $30 \%$, atomic) typical of metal surfaces. Depth profiling indicated that the carbon was only on the surface and that the oxide layer was $15 \mathrm{~nm}$ thick. Since the cooling of the tungsten layers was done in atmosphere, growth of an oxide layer during each pass of the plasma torch could lead to significant quantities of oxygen contamination within the coating. To examine the internal layer surfaces, a sample was fractured and examined by a JEOL-6400 SEM. Measurements of the atomic percentage of oxygen (by Energy Dispersive X-Ray Spectroscopy) were made at several locations on both the top surface of lamella and on the fractured surface. The concentrations on the outer lamella surfaces were comparable to those on internal surfaces and are in rough agreement with the $15 \mathrm{~nm}$ depth determined by AES (levels on the fractured surfaces were 3 
times lower). The observations are consistent with a HPPS growth sequence in which each newly deposited layer of tungsten forms an oxide surface, with incomplete bonding of the lamella to the next deposited layer. Since the vaporization of tungsten oxide occurs well below the melting point of tungsten, the vapor could provide a mechanism preventing the bond formation.

\section{Conditioning methodology}

Since the porous HPPS tungsten was not cleaned with solvents, it was expected that the hydrocarbon and water contamination on the plasma facing components in SSPX could be considerably higher than that found on smooth metal surfaces found in early tokamaks. For comparison, the use of glow discharge conditioning in PDX resulted in the removal of 100 monolayers of equivalent carbon ${ }^{9}$. For SSPX, the mass flow of volatile impurity species was used as a metric for evaluating the effectiveness of the initial conditioning.

The initial conditioning of the HPPS tungsten consisted of baking for water removal, glow discharge conditioning (GDC) for surface hydrocarbons and oxide reduction, and shot conditioning to remove residual surface contamination and more deeply trapped impurities (by surface heating). During this time period (May - August and October 1999), conditioning periods were inter-dispersed between machine operations (one partial loss of vacuum) and diagnostic installations. Following this period, Ti gettering of the HPPS tungsten has been used to improve vacuum conditions and reduce plasma impurity levels.

The SSPX vessel (volume 7900 liters) is pumped by a 1000 liter/second $\left(\mathrm{H}_{2}\right)$ turbomolecular pump, backed by an oil free scroll pump. Up to pressures of $10^{-4} \mathrm{Torr}$, the vessel pumping speed 
is conductance limited by the pumping duct (550 liter/second). GDC is operated at pressures above $10^{-4}$ Torr, where the pumping speed for $\mathrm{H}_{2}$ and other volatile impurity species is significantly lower. The GDC working gas pressure above $10^{-3}$ Torr is measured by a 10 Torr (now 1 Torr) capacitance manometer. Residual gas pressures in the vessel are monitored by a differentially pumped mass spectrometer (1-100 amu). Sampling of the vessel gasses during GDC is done through a restricted conductance valve to keep the total pressure at the mass spectrometer below $10^{-4}$ Torr. To relate the partial pressure of volatile impurity species in the vessel to those at the mass spectrometer during GDC, several factors must be estimated. The mass spectrometer response is a factory calibration, giving only an approximate partial pressure for each dominant mass peak. The measured $\mathrm{H}_{2}$ pressure ratio (vessel pressure / mass spectrometer pressure $\approx 2500$ ) was scaled by the square root of the mass ratio, but not corrected for the mass dependence of the pumping speed. The uncertainty in using these approximations limits the accuracy of the mass flow to an order of magnitude.

\section{Results}

Figure 4 shows a thermal desorption spectrum for a $125 \mu \mathrm{m}$ thick HPPS tungsten coating as measured in the Armor Conditioning Experiment (ACX) at Sandia. 18\% of the water was removed during the first 3000 seconds by ramping the temperature to $210^{\circ} \mathrm{C}$ (SSPX vessel temperature limit), with another $80 \%$ being removed by maintaining this temperature for about 70 hours (the remaining $2 \%$ was desorbed through a thermal ramp to $600^{\circ} \mathrm{C}$ ). From the shape of the water desorption curve, it is clear that temperatures above $150^{\circ} \mathrm{C}$ are adequate to remove water. While this system was not absolutely calibrated for water removal rates, the quantity of water liberated greatly exceeds other non-porous metals examined and is larger than any of the other volatile impurities liberated from this sample. 
Similar trends were observed in the residual gas analysis made during bake-out cycles in SSPX, where $\mathrm{H}_{2} \mathrm{O}$ dominates the initial vessel pressure by at least a factor of 10 . The partial pressure of mass $16,18,28,32$, and 44 are all reduced by an order of magnitude by baking the vessel at 170 $180^{\circ} \mathrm{C}$ for 400 hours. Baking is typically operated until the $\mathrm{H}_{2} \mathrm{O}$ peak falls significantly below the $\mathrm{H}_{2}$ peak (ultimate pressure of $10^{-7}$ Torr).

During $\mathrm{H}_{2}$ plasma operations, it was observed that $\mathrm{H}_{2} \mathrm{O}$ levels could rise to pre-bake levels, dominating the residual gas spectrum. Since it is well known that reduction of tungsten oxide by hydrogen occurs if the temperature approaches $600{ }^{\circ} \mathrm{C}$, it is possible that either (1) small regions of the HPPS tungsten coating are heated to high temperatures during discharges, or (2) hydrogen ion induced reduction can occur at lower temperatures. Tungsten oxide does not volatilize below $800^{\circ} \mathrm{C}$, therefore reduction should occur first. Observations of the $\mathrm{H}_{2} \mathrm{O}$ and $\mathrm{D}_{2} \mathrm{O}$ partial pressures during the first deuterium plasma operations also indicate the formation of water in the HPPS tungsten coating. Following a set of He fueled discharges, water levels were observed to rise several orders of magnitude, first during a set of $\mathrm{H}_{2}$ fueled discharges (mass 18), and then during a set of $\mathrm{D}_{2}$ fueled discharges (mass 20). This level of $\mathrm{D}_{2} \mathrm{O}$ is too large to result from the isotopic abundance of ${ }^{2} \mathrm{H}\left(1.5 \times 10^{-4}\right)$ or ${ }^{18} \mathrm{O}\left(2 \times 10^{-3}\right)$ while isotopic exchange is slow and would result in a reduction of the mass 18 peak.

During initial operation of SSPX, hydrogen GDC was used routinely to reduce surface hydrocarbon and oxide levels. The hydrogen pressure varied from a lower limit of $40 \mathrm{mTorr}$ needed to sustain the sheath to 120 mTorr required to access the gap between the inner and outer 
electrodes. The reduced pumping speeds obtained at these pressures is shown in Table 2. The pumping speeds of volatile impurity gases produced by the GDC are measured by fitting their pump-out curves in the working gas flow (see Figure 5).

\begin{tabular}{|c|c|c|c|c|}
\hline Pressure & & Pumping speed & Gas flow & Residence time \\
\hline & & & & \\
\hline 40 mTorr & & 35 liter / second & 1.3 Torr liter / second & 220 seconds \\
\hline 120 mTorr & & 16 liter / second & 1.9 Torr liter / second & 500 seconds \\
\hline
\end{tabular}

Table 2

The glow discharge current is supplied by a current limited, $600 \mathrm{~V}, 11.25 \mathrm{~A} \mathrm{DC}$ power supply, using a $1 \mathrm{ohm}$ resistor in series to measure the current. Typical working voltages vary between 250 to $400 \mathrm{~V}$, with currents ranging from 100 to 1400 milliamps. The voltage required for a given current has decreased as the wall conditions have improved. During the initial period of operations, the inner electrode was alternatively biased as cathode and anode. Simultaneous conditioning of all tungsten surfaces is now possible using a movable anode $(3.8 \mathrm{~cm} \times 12.7 \mathrm{~cm})$. During operation with the inner electrode as anode (or using the movable anode), the glow can extend through gaps in the flux conserver into the larger SSPX vacuum vessel.

Figure 5 shows the evolution of volatile impurity species during a typical shift of hydrogen GDC following a vessel bake-out. The dominant species $\left(\mathrm{CO}\right.$ and $\left.\mathrm{CH}_{4}\right)$ and $\mathrm{CO}_{2}$ increase by $1.5-3$ during the discharge while $\mathrm{O}_{2}$ and $\mathrm{H}_{2} \mathrm{O}$ do not show an increase. Oxygen is typically difficult to observe in vacuum systems while the $\mathrm{H}_{2} \mathrm{O}$ production through $\mathrm{GDC}$ has been shown to be negligible ${ }^{10}$. Operation with helium as the working did not increase the volatile impurity species pressures. Dylla ${ }^{11}$ has attributed this effect on stainless steel to the role of atomic hydrogen in the formation of $\mathrm{CH}_{4}, \mathrm{CO}$, and $\mathrm{CO}_{2}$ in the hydrocarbon / oxide layer on the metal surface. 
The mass flow out of the vessel can be estimated from the partial pressures of volatile impurities and their pumping speeds in the working gas: $Q_{x}=S_{x} p_{x}$. Using a typical partial pressure of $1 \times 10^{-}$ ${ }^{7}$ Torr for CO and a typical impurity pumping speed $\left(\mathrm{S}_{28} \approx 22\right.$ liter / second at $\left.80 \mathrm{mTorr}\right)$ yields $5.5 \times 10^{-3}$ Torr liter / second, or $1.9 \times 10^{17}$ carbon atoms / second. Using the appropriate surface area from Table 2 , this represents approximately 0.01 monolayers of carbon equivalent / second being removed by the GDC.

During the initial period of SSPX operations, hydrogen GDC was performed for 32.5 hours on the inner electrode (inner electrode as cathode) and for 15.5 hours on the outer electrode and flux conserver (inner electrode as anode). For nearly identical hydrogen pressure and current, the GDC partial pressures of $\mathrm{CO}, \mathrm{CH}_{4}$, and $\mathrm{CO}_{2}$ decreased by only a factor of 2 over this four-month period. Since the above rates would imply several 100 equivalent monolayers of $\mathrm{C}$ removal, the modest drop in removal rate of carbon is in marked contrast to experience on early metal wall tokamaks ${ }^{9,12}$, where the observed drops in removal rates were about 2 orders of magnitude. This indicates a considerably thicker hydrocarbon / oxide layer than that found on the top surface of the HPPS tungsten samples or a typical metal surface.

Figure 6 shows volatile partial pressures measured for conditioning shots during initial period of SSPX operations. An average of the peak partial pressures from 3 discharges is used for each point on the plot. $\mathrm{H}_{2} \mathrm{O}$ and $\mathrm{CO}_{2}$ are observed to drop by over a factor of 10 during this period; however, the $\mathrm{CO}$ and $\mathrm{CH}_{4}$ partial pressure drops are not as large. While a direct comparison with 
the volatile removal rates is difficult, the removal rate of equivalent carbon for shot conditioning appears to be smaller than that obtained during GDC.

Observations of the HPPS tungsten surfaces suggest that the majority of this conditioning is occurring on the inner electrode (cathode). A low density of arc tracks observed prior to this period grew to cover all of the surfaces in direct contact with the formation and spheromak plasma. The localized heating which occurs during arcing can remove more deeply trapped impurities than is accessible to the GDC.

Recent operation in SSPX has benefited from titanium gettering of the HPPS tungsten surfaces.

Residual gas analysis suggests that $\mathrm{H}_{2} \mathrm{O}$ is well pumped, while $\mathrm{CO}$ and $\mathrm{CO}_{2}$ exhibit some pumping. $\mathrm{CH}_{4}$ and other hydrocarbons are not pumped and the $\mathrm{H}_{2}$ pumping capacity of the film is approximately the gas fueling of one discharge. The affect of Ti gettering on plasma performance is described by Wood ${ }^{4}$.

\section{Summary}

We have characterized the HPPS tungsten using both in-situ studies and ex-situ measurements of samples. In-situ $\beta$ back-scattering has been used to show that the coating exceeds its nominal value of $100 \mu \mathrm{m}$ on all surfaces except in the plasma formation region of the inner electrode. Micrographs and thermal desorption of samples have shown a connected, porous structure capable of absorbing high levels of water. Baking, hydrogen GDC, and shot conditioning have been used to reduce water and surface hydrocarbon levels. Laboratory measurements and results from SSPX bake-out cycles have indicated that the $230^{\circ} \mathrm{C}$ baking capability of SSPX is sufficient to remove large amounts of water. The effectiveness of GDC and shot conditioning 
has been evaluated using removal rates of carbon calculated from the volatile species liberated by the plasma. In-situ mass spectrometry indicated initial carbon removal rates of roughly 0.01 monolayer / second during hydrogen glow discharge conditioning at 100 mTorr (abnormal glow). While GDC is used to condition the inner electrode and outer electrode / flux conserver, shot conditioning is most effective in removing impurities from in the inner electrode, with $\mathrm{CO}_{2}$ and $\mathrm{H}_{2} \mathrm{O}$ production dropping by a factor of 10 over $\approx 1000$ shots. Titanium getting on the tungsten surfaces has been used to increase the pumping for some of the volatile impurity species, but effective pumping of hydrogen has been limited.

\section{References}

'T. R. Jarboe, F. J. Wysocki, J. C. Fernandez, I. Henins, and G. J. Marklin, Nucl. Fusion, 30 (1991) 67.

${ }^{2}$ T. K. Fowler, Fusion Technol., 29 (1996) 206).

${ }^{3}$ E. B. Hooper, J. H. Hammer, C. W. Barnes, J. C. Fernandez, and F. J. Wysocki, Fusion Technol. 29 (1996) 191.

${ }^{4}$ R. D. Wood, D. N. Hill, E. B. Hooper, D. Buchenauer, A. Ahmed, and K. I. Thomassen, these proceedings (PSI-14).

${ }^{5}$ E. B. Hooper, L. D. Pearlstein, and R. H. Bulmer, Nucl. Fusion 39 (1999) 863.

${ }^{6}$ P. M. Bellan, Spheromaks, A Practical Application of Magnetohydrodynamic Dynamos and Plasma Self-Organization (2000, Imperial College Press, London, UK), Chapter 7.

${ }^{7}$ C. Garcia-Rosales, S. Deschka, W. Hohenauer, R. Duwe, E. Gauthier, J. Linke, M. Lochter, K. W. M .Mallener, L. Plochl, P. Rodhammer, A. Salito, and the ASDEX-Upgrade Team, Fusion Technol. 32 (1997) 263.

${ }^{8}$ B. E. Mills, D. A. Buchenauer, and A. E. Pontau, J. Nucl. Mater. 162 \& 164 (1989) 343.

${ }^{9}$ H. F. Dylla, S. A. Cohen, S. M. Rossnagel, G. M. McCracken, and Ph. Staib, J. Vac. Sci. Technol 17 (1980) 286.

${ }^{10}$ H. F. Dylla, J. Vac. Sci. Technol. A6 (1988) 1276. 
${ }^{11}$ H. F. Dylla, in: Surface Conditioning of Vacuum Systems, eds. R. A. Langley, D. L. Flamm, H. C. Hseuh, W. L. Hsu, and T. W. Rusch (American Institute of Physics, New York, 1990) p 3.

${ }^{12}$ W. Poschenreider, G. Staudenmaier, and P. Staib, J. Nucl. Mater. 93 \& 94 (1980) 322. 


\section{Figures captions}

Figure 1.

Cross sectional view of the toroidally symmetric SSPX device, showing the inner and outer electrodes, bias field coils, and flux conserver.

Figure 2.

Toroidal scans showing thickness of the HPPS tungsten coating on the flux conserver (horizontal surface) and inner electrode (end radius, $25 \mathrm{~cm}$ from end, $41 \mathrm{~cm}$ from end).

Figure 3.

Optical micrograph of a $125 \mu \mathrm{m}$ (nominal) thick HPPS coating on copper.

Figure 4.

Ionizer current from the mass spectrometer versus time from a $125 \mu \mathrm{m}$ (nominal) thick HPPS coating during thermal desorption.

Figure 5 .

Mass spectrometer partial pressures (sampled through the small conductance) observed during hydrogen GDC. Pumping speeds for the volatiles are calculated using the e-folding drop of pressure when the discharge is turned off. The glow current was not held constant during the first thousand seconds.

Figure 6.

Peak values of mass spectrometer partial pressures (sampled through the large conductance) generated by shot conditioning during the initial operations period. 
Figure 1

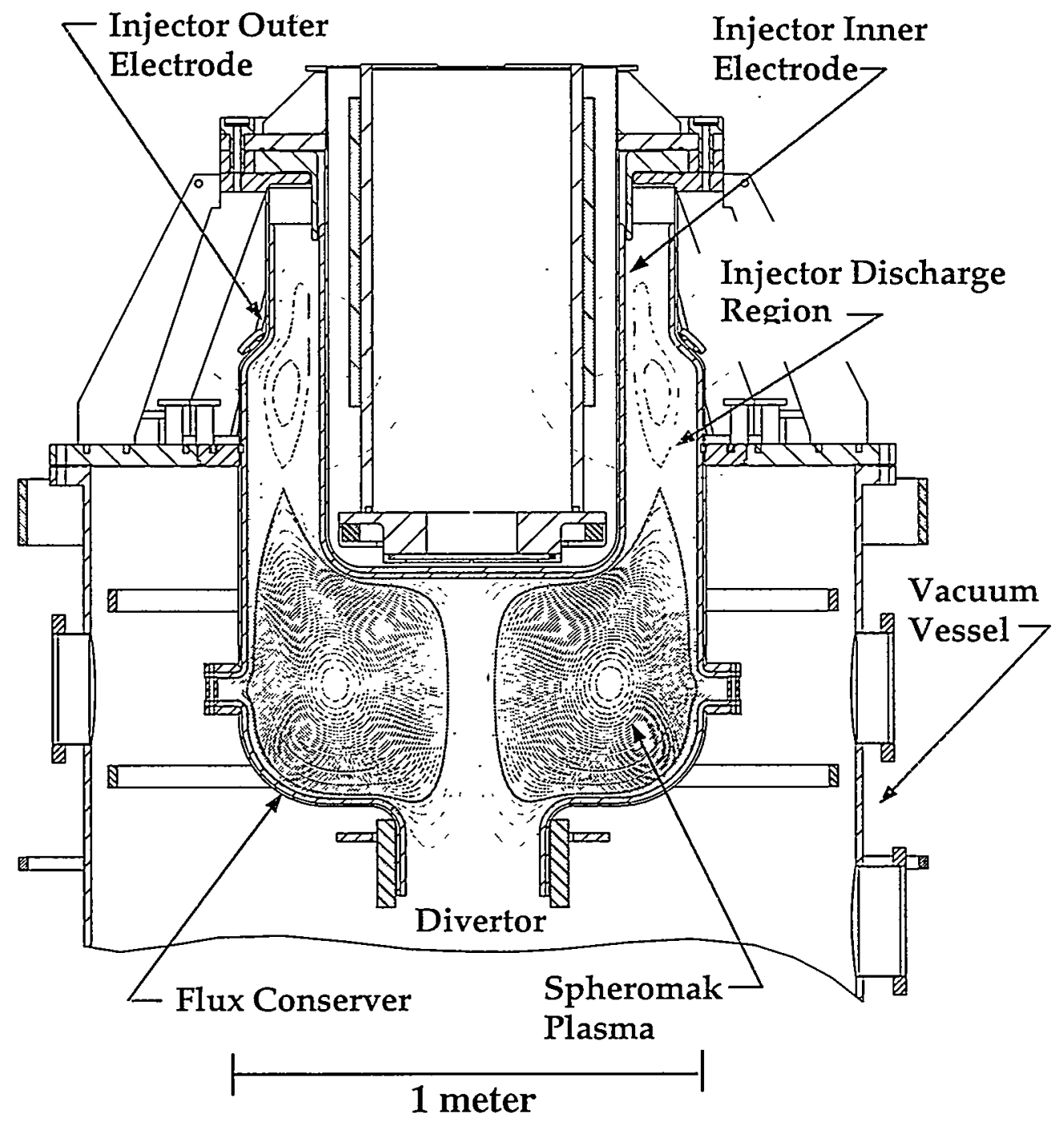


Figure 2

\section{HPPS Tungsten Coating Thickness from Beta-Backscatter}

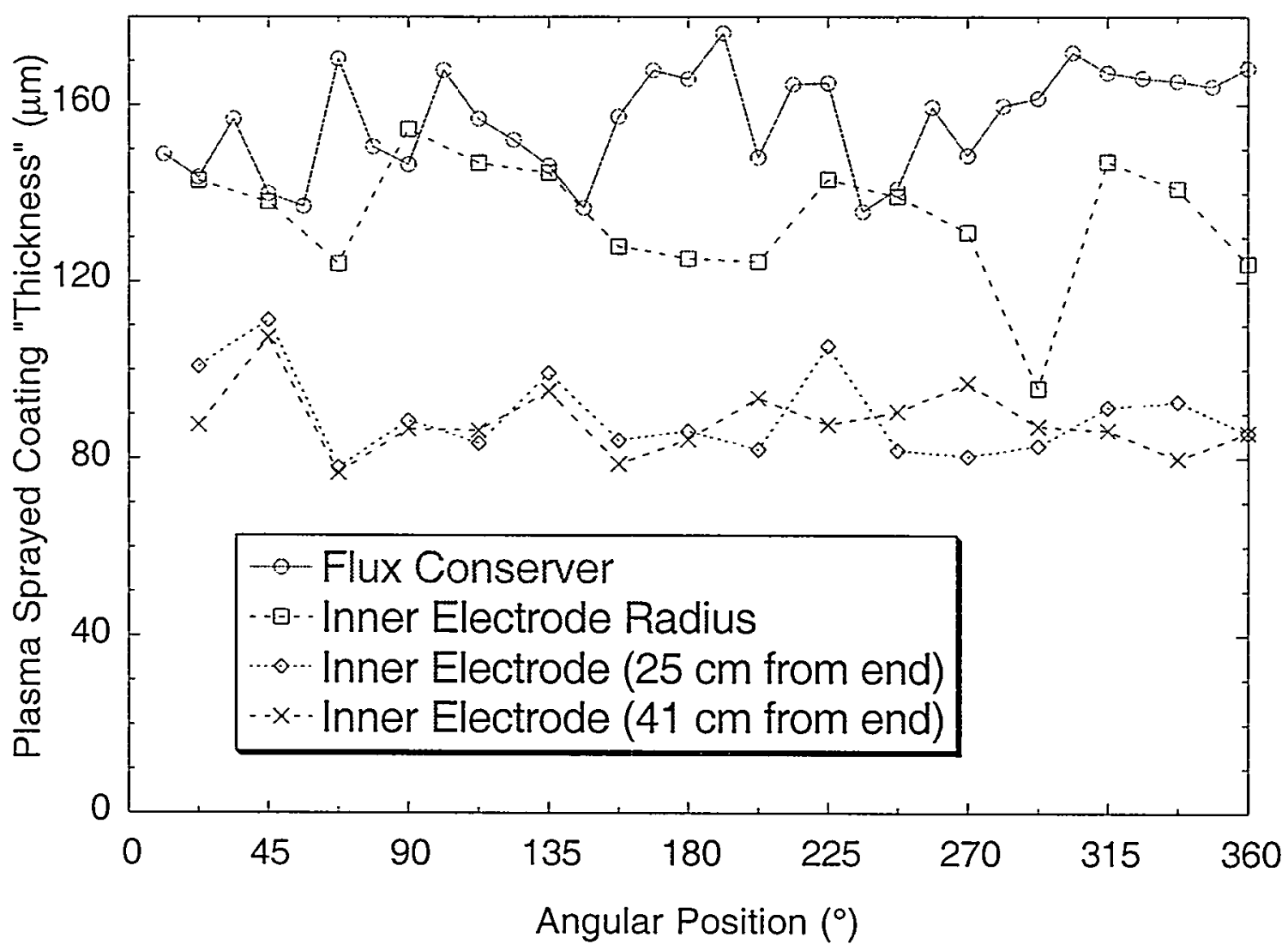


Figure 3

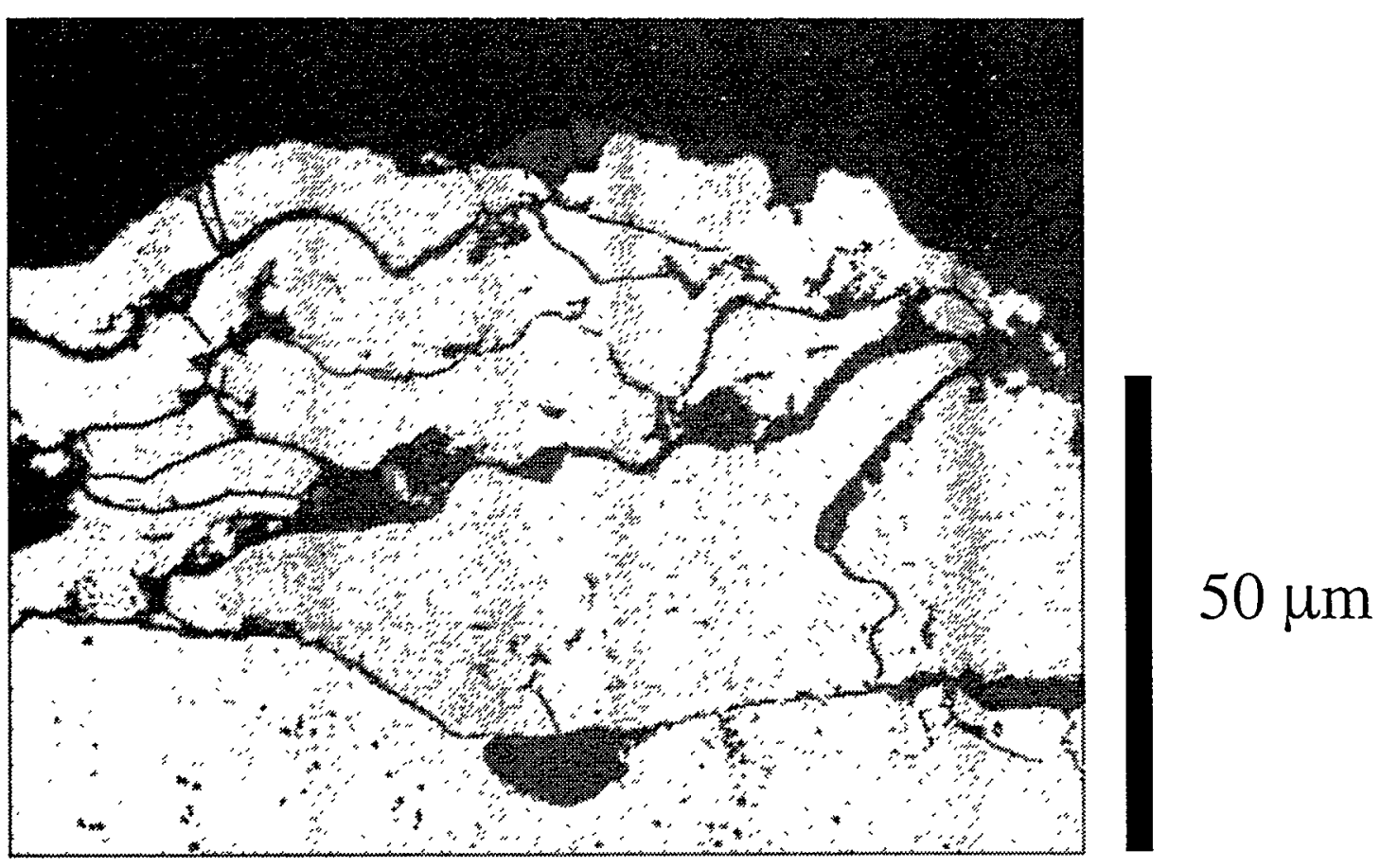


Figure 4

\section{HPPS Tungsten Thermal Desorption}

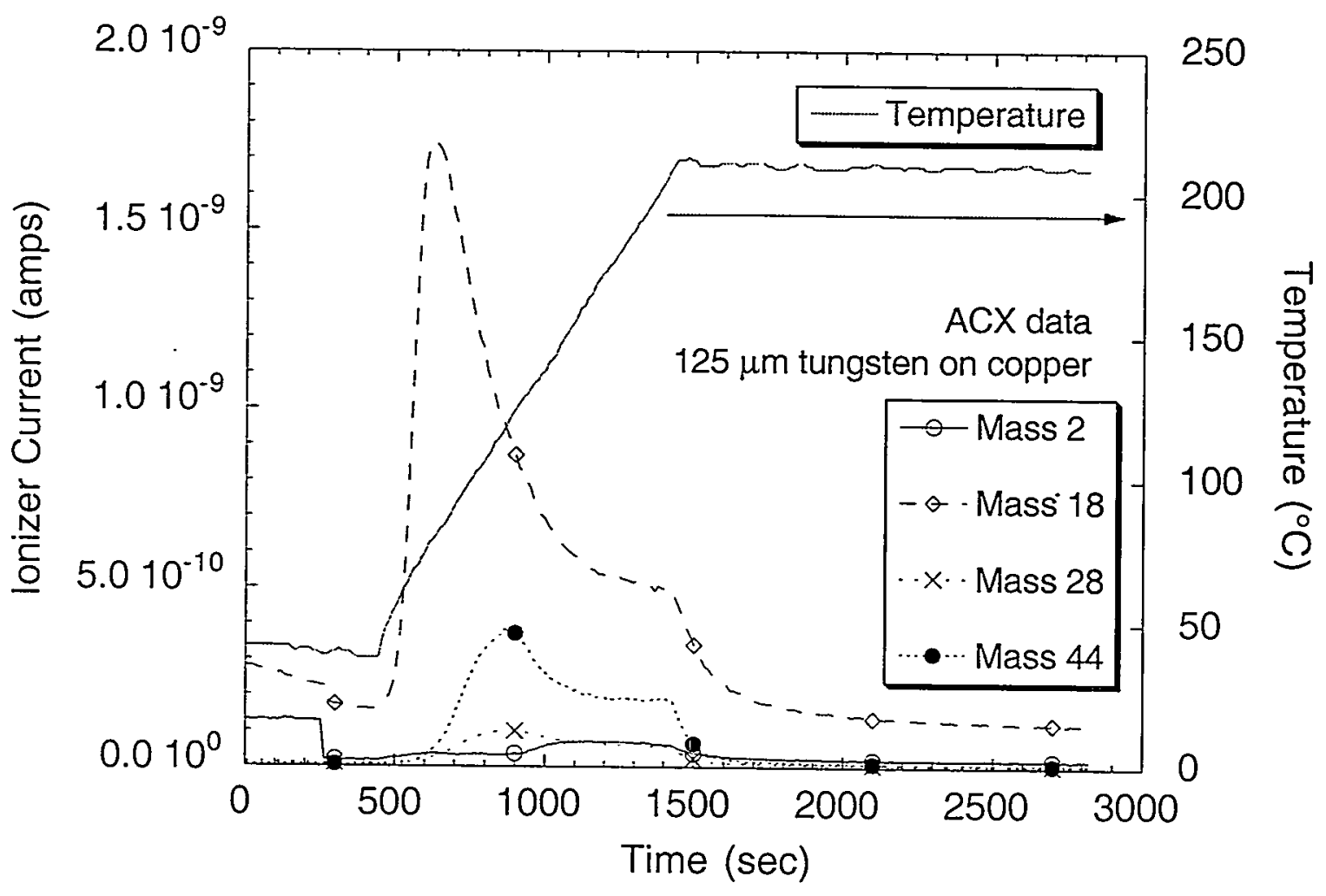


Figure 5

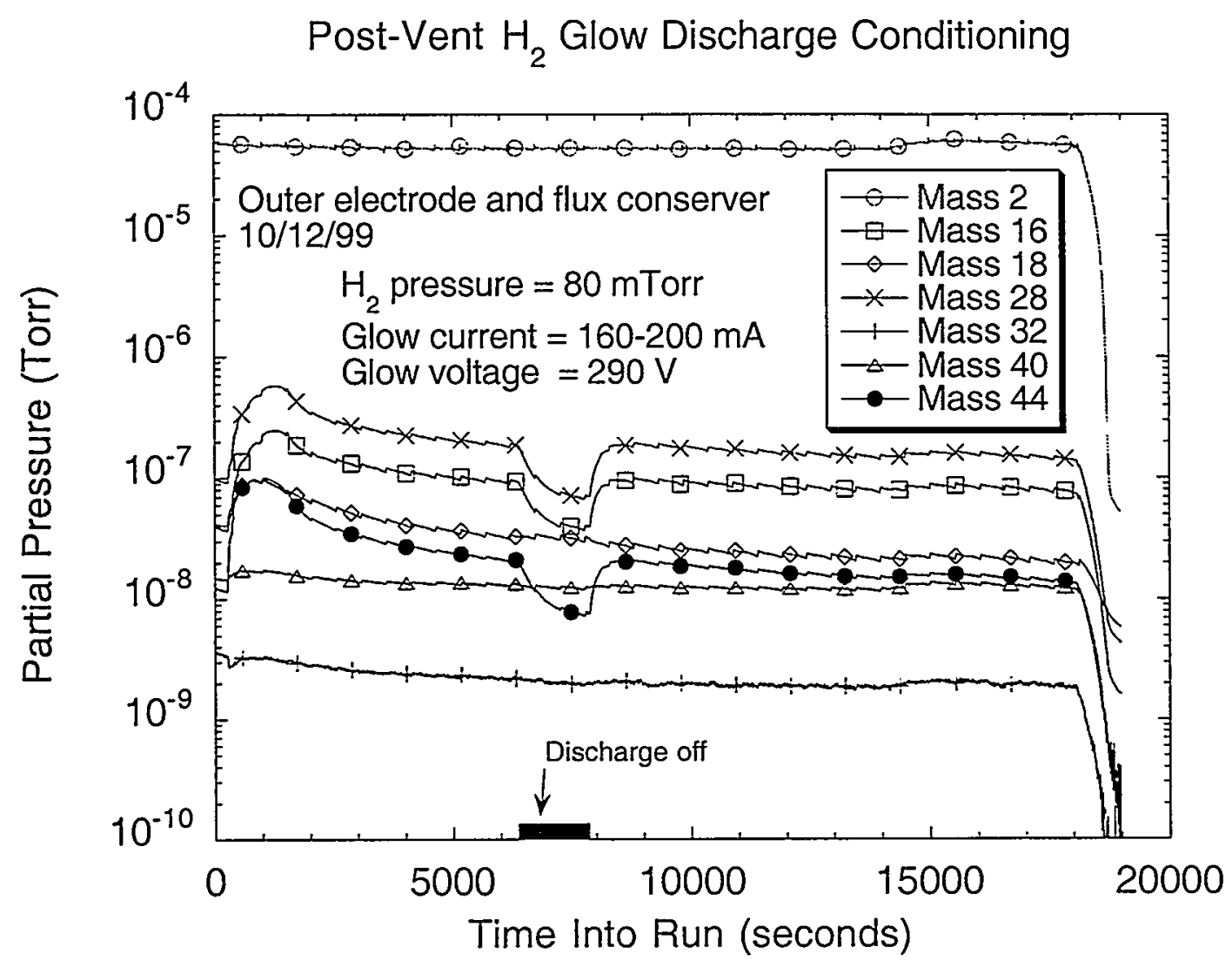


Figure 6

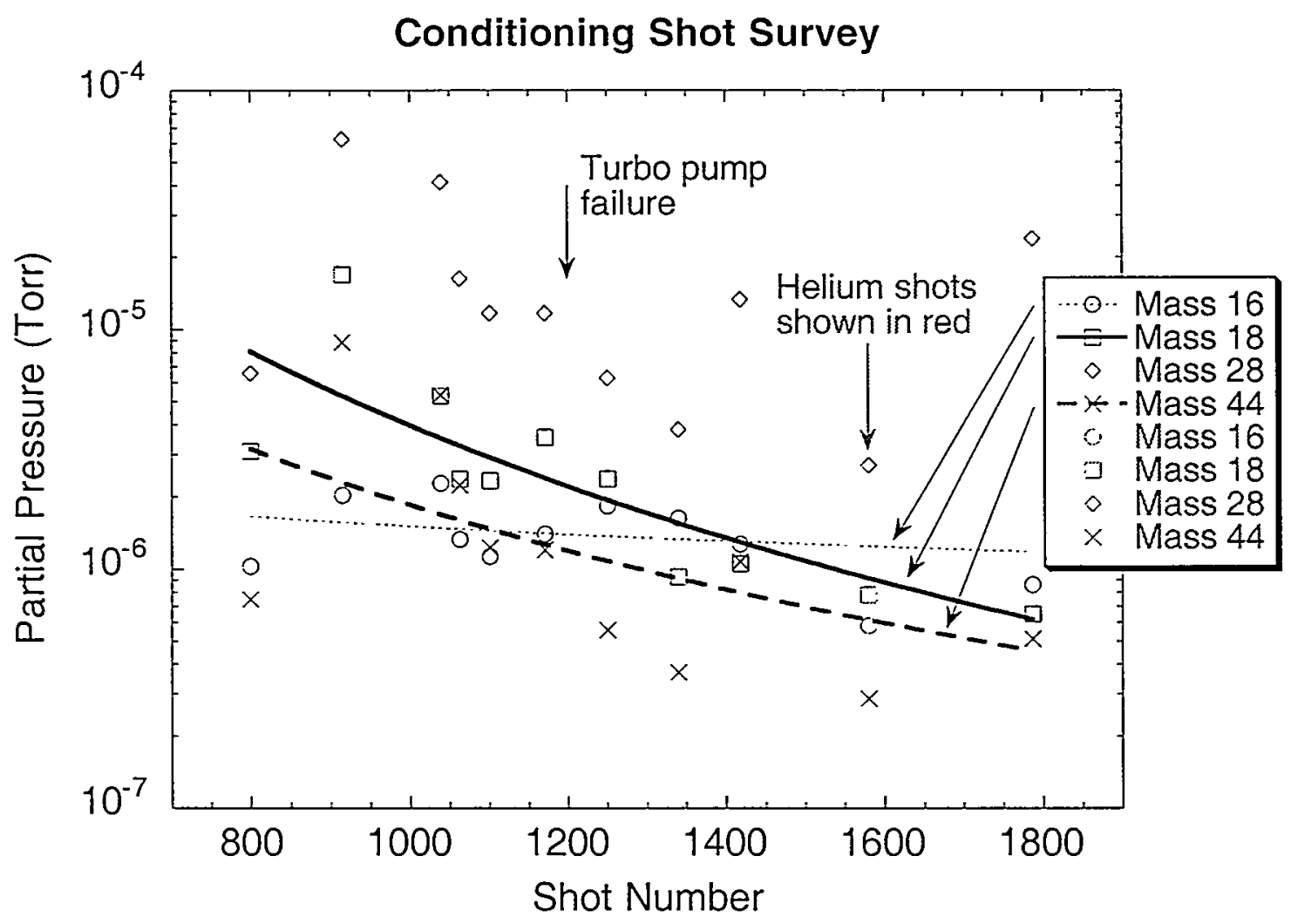

